\title{
Significance of changes in fetal perfusion pressure to factors controlling angiogenesis in the human term placenta
}

\author{
A. L. Karimu and G. J. Burton \\ Department of Anatomy, University of Cambridge, Downing Street, Cambridge, UK
}

\begin{abstract}
The objective of the study was to determine the effects of mechanical factors on endothelial proliferation in the human placental villous vasculature. Individual fetal lobules were perfused with tissue culture medium at two different standard pressures $(40$ and $100 \mathrm{~mm}$ $\mathrm{Hg}$ ). The perfused area was then removed and diced into small blocks which were quench frozen in liquid nitrogen. Cryostat sections were obtained and fixed in acetone at $4^{\circ} \mathrm{C}$. Proliferating cell nuclear antigen was then identified using $\mathrm{Ki} 67$ antibody as a marker. Proliferating nuclei were scored, using a light microscope, and a comparison made between the two pressures used. More proliferating endothelial nuclei were found at $100 \mathrm{~mm} \mathrm{Hg}$ than at $40 \mathrm{~mm} \mathrm{Hg}(P<0.05)$. It is therefore concluded that mechanical factors may play a role in villous angiogenesis and the formation of terminal villi.
\end{abstract}

\section{Introduction}

Angiogenesis can occur under both physiological and pathological conditions, and in all situations new vessel formation starts from the venous end of pre-existing capillaries (for example Ausprunk and Folkman, 1977; Folkman et al., 1981). The basement membrane is broken down by proteinases released from endothelial cells which convert plasminogen to plasmin. The plasmin in turn causes proteolysis of laminin and fibronectin, both components of the basement membrane. Endothelial cells protrude through the gaps in the basement membrane and migrate into the perivascular space where mitosis finally takes place (Glaser et al., 1983).

Various stimuli have been implicated in the regulation of angiogenesis. These include mechanical factors, such as increased transmural pressure, shear stress and interactions of erythrocytes with vascular endothelium (Myrhage and Hudlická, 1978; Hudlická and Tyler, 1986), and chemical factors such as changes in $\mathrm{pH}$ and hypoxia (Gospodarowicz et al., 1979; Knighton et al., 1981). It is difficult to determine which of these is the most important, and it is likely that under most conditions a combination of factors operate together (Hudlická and Tyler, 1986).

In the human placenta, angiogenesis is thought to play a role not only in the development of the villous vasculature but also in the formation of terminal villi. The development of terminal villi is believed to be controlled by the relative rates of longitudinal growth of mature intermediate villi and their contained capillaries (Kaufmann et al., 1985). As soon as growth of the capillaries exceeds that of the mature intermediate villi, the capillaries become coiled and form loops (Kaufmann et al., 1985; Benirschke and Kaufmann, 1990). The greater the disparity in growth rates, the more the capillaries become coiled. The capillary coils then obtrude from the surface of the mature intermediate villi, elevating domes of trophoblast and forming new terminal villi.

Along the course of capillaries within the terminal villi, focal dilatations calied sinusoids occur. In some areas, the sinusoids are particularly close to the overlying trophoblast so that the villous membrane may be as little as $1-2 \mu \mathrm{m}$ in thickness (Amstuz, 1960; Boyd and Hamilton, 1970; Ludwig, 1972; Fox and Agrofojo-Blanco, 1974). These areas, called vasculosyncytial membranes are well suited for gaseous exchange between mother and fetus (Boyd and Hamilton, 1970; Ludwig, 1972). As gestation advances, the vasculosyncytial membranes become more conspicuous and their surface area increases as a consequence of further enlargement of the sinusoids. It is believed that sinusoids may be the result of local remodelling or proliferation of endothelial cells on the outer wall of the capillary loops (Burton and Tham, 1992; Karimu and Burton, 1994).

Through the formation of terminal villi and vasculosyncytial membranes, the various factors affecting angiogenesis play crucial roles in determining the capacity of the placenta for diffusional exchange. However, the extent to which the different factors operate in the villous vasculature is not known. The present study was undertaken to determine the effects of mechanical factors on endothelial proliferation in the villous vasculature. Experiments were carried out in which individual placental lobules were perfused with tissue culture medium at two different standard pressures. Activation of endothelial proliferation was demonstrated by labelling with $\mathrm{Ki} 67$ antibody which binds to cyclin and proliferating cell nuclear antigen in actively dividing cells. It is a quicker alternative to conventional autoradiographic methods.

\section{Materials and Methods}

\section{Placental material}

The approval of the local Ethical Committee and consent of the patients were obtained for the use of placental material. The 
placental material was obtained from ten normal singleton pregnancies delivered by Caesarian section at 38-40 weeks gestation, for cephalopelvic disproportion with no complicating maternal pathology such as hypertension or diabetes mellitus. All sections resulted in live births. The umbilical cords were usually clamped within I min of delivery.

After inspecting the placenta to rule out areas of obvious pathology such as infarction, an artery and its accompanying veins supplying an area of the placental disc close to the periphery was chosen. The vessels were cannulated and the placental lobe placed in a bath of physiological saline.

Compressed air $\left(95 \%\right.$ air and $\left.5 \% \mathrm{CO}_{2}\right)$ from a cylinder, controlled by a needle valve, provided the pressure required to perfuse the fetal circulation. In the first five placentae, a pressure of $40 \mathrm{~mm} \mathrm{Hg}$ was applied, while in the second five placentae, a pressure of $100 \mathrm{~mm} \mathrm{Hg}$ was applied. A bottle containing $1 \mathrm{l}$ of Medium 199 (Sigma, Poole), 10\% (v/v) calf serum (Sera-Lab, Sussex), $0.1 \mathrm{~g}$ glutamine (Flow Laboratory, Costa Mesa, CA) and $10 \mathrm{ml}$ of antimycotic/antibiotic (Sigma) $\mathrm{pH} 7.2-7.4$ was fed into the cannula to perfuse the placental lobe. The perfusate emerging from the venous cannula was collected into another bottle and recirculated through the placental lobe with the aid of a peristaltic pump. A continuous circulation was therefore maintained over $6-8 \mathrm{~h}$. The whole system was maintained at $37^{\circ} \mathrm{C}$ in a water bath. The perfused area was then removed and diced into five small blocks, cryoprotected and quench frozen in melting propane cooled in liquid nitrogen. Cryostat sections ( $4 \mu \mathrm{m}$ thick) were obtained and floated on formol-gelatine coated slides. The sections were air dried briefly and fixed for 5-10 min with acetone at $4^{\circ} \mathrm{C}$.

\section{Immunohistochemistry}

Tissue sections were rehydrated and incubated with blocking serum $2 \%(\mathrm{w} / \mathrm{v}) \mathrm{BSA}$ and $10 \%(\mathrm{v} / \mathrm{v})$ normal goat serum diluted with PBS for $20 \mathrm{~min}$. This was followed by incubation with Ki67 antibody (1:25 dilution; Dako Ltd, High Wycombe) for $30 \mathrm{~min}$ at room temperature. The second stage antibody was an anti-IgG/IgM, biotinylated antibody used at a dilution of 1:500, in which sections were incubated for $30 \mathrm{~min}$ at $4^{\circ} \mathrm{C}$. This was followed by incubation with peroxidase conjugated streptavidin (Dako Ltd; diluted according to manufacturer's instructions) for $30 \mathrm{~min}$ at $4^{\circ} \mathrm{C}$. Violet coloured immunoperoxidase substrate from Vector Laboratories (Peterborough) was used as a chromogen. Each step was followed by a wash in PBS. The sections were counterstained with haematoxylin for $30 \mathrm{~s}$. The primary antibody was replaced with PBS in the control group, but all other steps were similar.

\section{Scoring of Ki67 labelled nuclei}

Scoring of proliferating nuclei was performed using a light microscope at a final magnification of $\times 1250$. All nuclei exhibiting staining were counted. Starting from a random point and then moving systematically in the $x-y$ direction, the number of both positively labelled cytotrophoblastic and endothelial nuclei per villous profile were counted. A total of

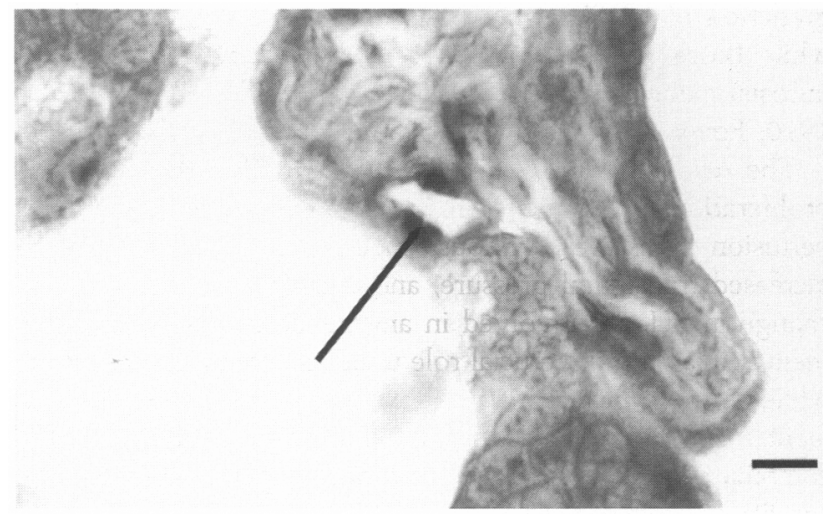

Fig. 1. Proliferating villous capillary endothelial nucleus (arrow) stained with Ki67 antibody. Scale bar represents $9 \mu \mathrm{m}$.

100 villous profiles per pressure group was counted for each placenta.

\section{Statistical analysis}

The results of the two pressure groups were compared using Student's $t$ test.

\section{Results}

The quality of tissue preparation was excellent, as shown by the villous morphology, including distinct identification of the different villous components (trophoblasts, stroma and capillaries).

Nuclear staining was observed with both pressures used. The positive nuclei ranged from light to deep purple, with minimal background staining of the cytoplasm. The nonproliferating nuclei (trophoblastic and endothelial) were counterstained blue by haematoxylin.

The positively stained nuclei were mainly endothelial, although a few cytotrophoblastic nuclei were also observed (Fig. 1).

There were more positively stained endothelial nuclei at $100 \mathrm{~mm} \mathrm{Hg}(1.96 \pm 0.18)$ than at $40 \mathrm{~mm} \mathrm{Hg}(0.86 \pm 0.11)$ and this difference was statistically significant $(P<0.05)$. However, there was no significant difference in the number of labelled cytotrophoblastic nuclei between the pressure groups $(0.27 \pm 0.06$ and $0.25 \pm 0.06$, respectively). This provided a positive control that the labelling efficiency of the primary antibody was similar in the two series.

\section{Discussion}

Proliferating cell nuclear antigen (PCNA) is a $36 \mathrm{kDa}$ auxiliary protein to DNA polymerase delta (Matthews et al., 1984). It is found in various concentrations within the cell throughout the cell cycle and in greatest quantity during S-phase (Celis and Celis, 1985). The use of Ki67 antibody labelling on frozen sections as an indication of cell proliferation is well established (e.g. Kamel et al., 1991). There is a 
gradation of labelling, and cells in S-phase stain very deeply while those not in $S$ phase (for example at G2 phase and mitosis) exhibit only weak staining (Battersby and Anderson, 1990; Foley et al., 1991).

The results of the present study show that the number of proliferating endothelial cell nuclei increases with increasing perfusion pressure. Various mechanical factors, such as increased transmural pressure, and chemical factors, such as a change in $\mathrm{pH}$, are involved in angiogenesis. Chemical factors seem to play a more crucial role under pathological conditions, while mechanical factors are more important during development and in normal tissues (Hudlická and Tyler, 1986). A combination of both factors is probably operating under most conditions.

Increased intravascular pressure is an important factor stimulating the growth of new vessels (Bevan, 1976; Berry, 1978). Bevan (1976) found good correlation between the increased incorporation of $\left[{ }^{3} \mathrm{H}\right]$ thymidine into arterial smooth muscle cells and arterial pressure. Increased blood flow associated with increased vascular pressure has been observed to induce capillary growth in all contracting muscles (Kasalicky et al., 1977). It is probable, however, that the various components of increased flow, such as increased velocity, wall tension, shear stress and interaction of endothelial cells with erythrocytes, play synergistic roles in angiogenesis (Hudlická and Tyler, 1986).

The findings of the present study demonstrate that increased perfusion pressure plays a significant role in stimulating villous angiogenesis. This in turn may control the formation of terminal villi and their vasculosyncytial membranes. The capillaries within the terminal villi follow a tortuous course and, at points of bends, display sinusoidal dilatation (Boyd and Hamilton, 1970; Kaufmann et al., 1985). It has been proposed that these dilatations result from a combination of high transmural pressure and shear stress exerted on the outer surface of the bend (Burton and Tham, 1992) which ultimately promote local endothelial proliferation in the outer wall of the bend (Hudlicka and Tyler, 1986). Consequently the capillary tends to balloon outwards towards the overlying syncytiotrophoblast, reducing the intervening stromal distance and forming a vasculosyncytial membrane.

Karimu and Burton (1994) demonstrated that the placental capillaries are compliant. The capillary volume fraction and ratio of capillary to villous surface area increases with increasing fetal perfusion pressure, as a result of preferentially orientated dilatation of capillary sinusoids in the region of vasculosyncytial membranes. If the fetal perfusion pressure remains high for a long time, local endothelial cell proliferation will ensue. Through this mechanism, placental differentiation may be matched to the respiratory demands of the fetus (Burton and Feneley, 1992). There is, however, an underlying assumption that the peripheral placental vasculature is exposed to forces which reflect the dynamics of fetal circulation in vivo. As placental circulation is of low resistance and operates at maximal dilatation under normal conditions (Rankin, 1989; Boura and Walter, 1991), this probably occurs. The results of this study therefore provide strong evidence in support of a role of mechanical factors in the regulation of villous angiogenesis.
A combination of mechanical and chemical factors are probably involved in vivo. During fetal hypoxia, peripheral vasoconstriction results in increased fetal blood pressure and diversion of flow within the descending aorta to the umbilical circulation (Mott and Walker, 1983). At the same time there is an accumulation of metabolites such as ADP and lactic acid, which are known to be angiogenic (D'Amore and Shepro, 1977; Fraser and Simpson, 1983). Moreover, growth promoting factors such as vascular endothelial derived growth factor, platelet derived growth factor and epidermal growth factor are also released under these conditions (Ross et al, 1974; Karnovsky, 1981). Chronic hypoxia may therefore stimulate angiogenesis by a combination of mechanical and chemical factors, the result of which is structural adaptation to improve fetal oxygenation.

A. L. Karimu was supported by a scholarship from the Commonwealth Scholarship Commission in the UK. The authors thank K. J. Dalton, Consultant Obstetrician, and the nursing staff of the Rosie Maternity Hospital, Cambridge for the collection of the placental material. In this Department, the authors thank J. Bashford and members of staff of the Audio Visual Aid Unit for the figure and J. Seymour-Shove for typing the manuscript.

\section{References}

Amstuz E (1960) Beobachtungen über die Reifung der Chorionzotten in der menschlichen Placenta mit besonderer Berücksichtigung der Epithelplatten Acta Anatonica 42 122-130

Ausprunk DH and Folkman J (1977) Migration and proliferation of endothelial cells in preformed and newly formed blood vessels during tumor angiogenesis Microvascular Research 14 53-56

Battersby S and Anderson TJ (1990) Correlation of proliferative activity in breast tissue using PCNA/cyclin Human Pathology 21 781-784

Benirschke K and Kaufmann P (I990) Pathology of the Human Placenta (2nd Edn), pp 98. Springer-Verlag, Berlin

Berry CL (1978) Hypertension and arterial development: long term considerations British Heart Journal $\mathbf{4 0} 709-717$

Bevan RD (1976) An autoradiographic and pathological study of cellular proliferation in rabbit arteries correlated with an increase in arterial pressure Blood Vessels 13 100-128

Boura ALA and Walter WAW (1991) Autocoids and the control of vascular tone in the human umbilical-placental circulation Placenta $12453-477$

Boyd JD and Hamilton WJ (1970) The Human Placenta, p 151. Heffers, Cambridge

Burton GI and Feneley MR (1992) Capillary volume fraction is the principal determinant of villous membrane thickness in the normal human placenta at term Journal of Developmental Physiology 17 39-45

Burton GJ and Tham SW (1992) Formation of vasculosyncytial membranes in the human placenta Journal of Developmental Physiology 18 43-47

Celis JE and Celis A (1985) Cell cycle dependent variations in the distribution of the nuclear protein cyclin proliferation cell nuclear antigen in cultured cells: subdivision of S-phase Proceedings of the National Academy of Sciences USA $823262-3266$

D'Amore PA and Shepro D (1977) Stimulation of growth and calcium influx in cultured bovine aortic endothelial cells by platelets and vasoactive substances Journal of Cellular Physiology 92 177-184

Foley JF, Dietrich DR, Swenberg JA and Maronpot RR (1991) Detection and evaluation of proliferating cell nuclear antigen (PCNA) in rat tissue by an improved immunohistochemical procedure Journal of Histochemistry 14 $237-240$

Folkman JD, Ausprunk D and Langer R (1981) Connective tissue: small blood vessels and capillaries. In Textbook of Rheumatology Vol. 1 pp 210-220 Eds WN Kelley, ED Harris, S Roddy and CB Sledge. Saunders, Philadelphia

Fox $\mathrm{H}$ and Agrofojo-Blanco A (1974) Scanning electron microscopy of the human placenta in normal and abnormal pregnancies European Journal of Obstetrics and Gynecology and Reproductive Biology 4 45 -50 
Fraser RA and Simpson JG (1983) Role of mast cells in experimental tumour angiogenesis. In Development of the Vascular System, Ciba Foundation Symposium 100 120-131. Pitman, London

Glaser BM, Kalebic T, Garbisa S, Connor TB and Liotta L (1983) Degradation of basement membrane components by vascular endothelial cells: role in neovascularisation. In Development of the Vascular System, Ciba Foundation Symposium 100 150-162. Pitman, London

Gospodarowicz D, Bialecki H and Thakral TK (1979) The angiogenic activity of the fibroblast and epidermal growth factors Experimental Eye Research 28 $501-514$

Hudlická O and Tyler KR (1986) Factors involved in the growth of vessels. In Angiogenesis: The Growth of the Vascular System pp 151-171. Academic Press, London

Kamel OW, LeBrun DP, Davis RE, Berry GJ and Warnke RA (1991) Growth fraction estimation of malignant lymphomas in formalin-fixed paraffin embedded tissue using anti-PCNA/cyclin 19A2 American Joumal of Pathology $138 \quad 1471-1477$

Karimu AL and Burton GJ (1994) The effects of maternal vascular pressure on the dimension of fetal capillaries British Journal of Obstetrics and Gynecology $10157-63$

Karnovsky MJ (1981) Endothelial-vascular smooth muscle cell interactions American Journal of Pathology 105 200-206

Kasalicky J, Ress! J, Urbanová D, Widimsky J, Ostádal B, Pelouch V, Vízek H and Procházka J (1977) Relative organ blood flow in rats exposed to intermittent high altitude hypoxia Pflugers Archiv 368 111-115
Kaufmann P, Bruns U, Leiser R, Luckhardt M and Winterhager E (1985) The fetal vascularisation of term human placental villi. II Intermediate and terminal villi Anatomy and Embryology 173 203-214

Knighton DR, Silver IA and Hunt TK (1981) Regulation of wound healing angiogenesis: effect of oxygen gradient and inspired oxygen concentration Surgery 90 262-270

Ludwig KS (1972) The morphologic structure of the placenta in relation to its exchange function. In Respiratory Gas Exchange and Blood Flow in the Placenta pp 13-21 Eds LD Longo and H Bartels. US Department of Health, Education and Welfare, Bethesda

Matthews MB, Bernstein RM, Franza BR, Jr and Garrels JI (1984) Identity of the proliferating cell nuclear antigen and cyclin Nature 309 374-376

Mott JC and Walker DW (1983) Neural and endocrine regulation of circulation in the fetus and newborn. In Handbook of Physiology Section 2 Circulation, Vol III, Peripheral Circulation and Organ Blood Flow Part 2 pp 837-883. American Physiological Society, Bethesda

Myrhage R and Hudlická O (1978) Capillary growth in chronically stimulated adult skeletal muscle as studied by intravital microscopy and histological methods in rabbits and rats Microvascular Research 16 73-90

Rankin JHG (1989) Interaction between the maternal and fetal placental blood flows. In The Uterine Circulation pp 175-190 Ed. CR Rosenfeld. Perinatology Press, lthaca

Ross RJ, Glomset B, Kariya B and Harker L (1974) A platelet dependent serum factor that stimulates the proliferation of arterial smooth muscle cells in vitro Proceedings of the National Academy of Science, USA 71 1207-1210 